\title{
Stratosphere-troposphere exchange in an extratropical cyclone, calculated with a Lagrangian method
}

\author{
M. Sigmond, J. Meloen, P. C. Siegmund \\ Royal Netherlands Meteorological Institute (K.N.M.I.), PO Box 201, Wilhelminalaan 10, 3730 AE De Bilt, The Netherlands \\ Received: 10 September 1999 / Revised: 31 January 2000 / Accepted: 9 February 2000
}

\begin{abstract}
A Lagrangian technique is developed and applied to calculate stratosphere-troposphere exchange in an extratropical cyclone. This exchange is computed from the potential vorticity or $P V$ along trajectories, calculated from ECMWF circulation data. Special emphasis is put on the statistical significance of the results. The computed field of the cross-tropopause flux is dominated by elongated patterns of statistically significant large downward and small upward fluxes. The downward fluxes mainly occur in the lower part of the considered tropopause folds. The upward fluxes are found near the entrance of the folds, in the tropopause ridges. The ratio between the area averaged downward and upward cross-tropopause fluxes increases with increasing strength of the cyclone. Since the largest fluxes are shown to occur in the regions with the largest wind shear, where $P V$-mixing is thought to cause large cross-tropopause fluxes, the results are expected to be reliable, at least in a qualitative sense. The position of a tropopause fold along the northwest coast of Africa is confirmed by total ozone observations. The results indicate that the applied Lagrangian technique is an appropriate tool for diagnosing stratosphere-troposphere exchange.
\end{abstract}

Key words: Meteorology and atmospheric dynamics (general circulation; mesoscale meteorology; middle atmosphere dynamics)

\section{Introduction}

Understanding and quantifying human impact on the climate system is one of the most challenging questions

Correspondence to: P. C. Siegmund

e-mail: siegmund@knmi.nl in atmospheric sciences. The importance of stratosphere-troposphere exchange (STE) for understanding this impact is widely acknowledged (e.g. Holton et al., 1995). The transport of specific anthropogenic emissions from the ground to the stratosphere is believed to be the main cause of stratospheric ozone depletion (WMO, 1995), whereas the increasing aircraft emissions in the tropopause region could have a substantial impact on climate and the atmospheric composition (IPCC, 1999). The global scale STE is realised by a mean meridional cell, which is called the Brewer-Dobson circulation. The cell consists of upward cross-tropopause transport in the tropics, poleward drift in the stratosphere towards the winter pole, and downward transport into the extratropical winter troposphere (Brewer, 1949; Dobson, 1956).

At smaller scales, however, STE is not dominated by mean circulations, but by synoptic scale eddy processes, such as tropopause folds associated with cut-off lows, that can lead to rapid exchange of air across the tropopause (Holton et al., 1995). Therefore, apart from downward cross-tropopause transport, upward crosstropopause transport occurs in the extratropics, which can bring anthropogenic species directly into the extratropical lower stratosphere (e.g. Hoerling et al., 1993). Knowledge of the instantaneous bi-directional crosstropopause fluxes rather than the time-mean net flux is, in the presence of a cross-tropopause gradient of a chemical species, necessary to determine the fluxes of this species across the tropopause (Gettelman and Sobel, 1998). Moreover, since the anthropogenic species are emitted non-uniformly in time and space, the knowledge of the distribution of the instantaneous cross-tropopause flux (CTF) is essential for modelling the human impact on the climate.

Many efforts have been made to determine the CTF. In these studies, Eulerian diagnostic methods have been dominant. The CTF is generally computed with one of the versions of the diagnostic formula derived by Wei (1987) (hereafter called the Wei- $x$ formula, where $x$ is the vertical coordinate, see later). 
Hoerling et al. (1993) diagnosed the net global-scale CTF by applying Wei's (1987) equation to twice-daily global circulation data with a horizontal resolution of $3.75^{\circ} \times 3.75^{\circ}$. Siegmund et al. (1996) investigated the STE with a more accurate numerical method and with circulation data at higher temporal and spatial resolution. They calculated the magnitudes of the upward and downward cross-tropopause fluxes separately. They found that for an accurate estimation of the local and instantaneous CTF, the spatial and temporal resolution should be at least $1^{\circ} \times 1^{\circ}$ and $6 \mathrm{~h}$, respectively. To cope with practical problems of time and space differencing, a complicated numerical scheme is applied. Siegmund et al. (1996) as well as Gettelman and Sobel (1998) used the Wei- $p$ formula (where $p$ denotes pressure) and found strong dipole structures in the computed CTF field.

Wirth and Egger (1999) examined five different methods to diagnose the CTF in a cut-off low. They found that both the Wei- $p$ and the Wei- $\theta$ formula (where $\theta$ denotes potential temperature) are unreliable. In these formulas, the CTF is a small residual of three relatively large terms, so that small errors in the individual terms can result in a large relative error in the computed CTF. A third method examined by Wirth and Egger (1999) is the Wei- $P V$ formula, where potential vorticity is taken as the vertical coordinate. The advantage of this method is that if the tropopause is defined as a $P V$-surface, the formula consists of only one term. The method therefore does not suffer from the problem of strong cancellation, provided that the $P V$-sources can be calculated with reasonable accuracy.

Apart from these Eulerian diagnostic methods, Wirth and Egger (1999) also examined a Lagrangian method, by starting multiple trajectories on the tropopause. The pressure difference between the endpoint of a trajectory and the tropopause at that point is then considered as a measure for the STE in the considered time interval.

Wernli and Davies (1996) describe how their Lagrangian method can be applied to diagnose the CTF in an extratropical cyclone. Coherent ensembles of trajectories with a period of 10 days, which cross the tropopause (defined as the $2 P V U$ surface, $1 P V U=$ $10^{-6} \mathrm{~K} \mathrm{~m}^{2} \mathrm{~kg}^{-1} \mathrm{~s}^{-1}$ ), are identified. Only a small part $(5-25 \%)$ of these trajectories indicate significant STE (i.e. reside within the stratosphere (troposphere) during (at least) the first four days and within the troposphere (stratosphere) for (at least) the last four days). Although this method is an appropriate tool for studying the spatial structure of STE in an extratropical cyclone, it does not give a numerical estimate of the CTF.

In the present study a Lagrangian technique is used to calculate STE in an extratropical cyclone. Although this technique is to some extent similar to that applied by Wirth and Egger (1999), there are several new aspects in it. The main concept of our method is the evaluation along trajectories of the air mass flux across several $P V$ surfaces. In contrast to previous studies, the errors in the calculated data will be discussed.

In Sect. 2 the method, input data and the trajectory model will be described. The results will be presented in Sect. 3, discussed in Sect. 4 and summarised in Sect. 5.

\section{Method and data}

\subsection{Calculation of the air mass flux across a PV-surface}

In the present study Wei's (1987) general formula is used with $P V$ as the vertical coordinate. The air mass flux across a $P V$-surface per unit surface area $(F)$ is then defined by:

$F=-\frac{1}{g} \frac{\partial p}{\partial P V} \frac{\mathrm{d} P V}{\mathrm{~d} t}$,

where $g$ is the acceleration due to gravity. The unit of $F$ is $\mathrm{kg} \mathrm{m}^{-2} \mathrm{~s}^{-1}$.

For consistency, it is desired that positive values of $F$ near the tropopause would denote transport from the troposphere to the stratosphere in all cases. In order to accomplish this, Eq. (1) should be altered in the case of tropopause folds. A tropopause is folded where the $P V$ surface is multivalued with respect to pressure, i.e. at a particular longitude and latitude where three heights are found where $P V=$ constant. Consider the tropopause fold as in Fig. 1, where the air is transported from the troposphere to the stratosphere in all parts of the fold. Since the surface is turned upside down in the middle part of the fold, $\partial p / \partial P V$ is positive in that part. Calculating $F$ with Eq. (1) would then give a negative $F$ through this middle surface, whereas a positive value is desired. This problem can be solved by calculating $F$ as:

$F=\frac{1}{g}\left|\frac{\partial p}{\partial P V}\right| \frac{\mathrm{d} P V}{\mathrm{~d} t}$,

so that the sign of $F$ is determined by the sign of $\mathrm{d} P V / \mathrm{d} t$. Positive values of $F$ are then always associated with transport from the troposphere to the stratosphere.

To compute the right-hand side of Eq. (2), we calculate the $P V$ and $|\partial p / \partial P V|$ along trajectories. An example of the $P V$ along a trajectory is shown in Fig. 2. As can be inferred from Fig. 2, the $P V$ is partially fluctuating due to noise. The instantaneous $\mathrm{d} P V / \mathrm{d} t$ is therefore not reliable. In order to reduce this noise, the $P V$ should be averaged over a certain period. $F$ is therefore approximated as:

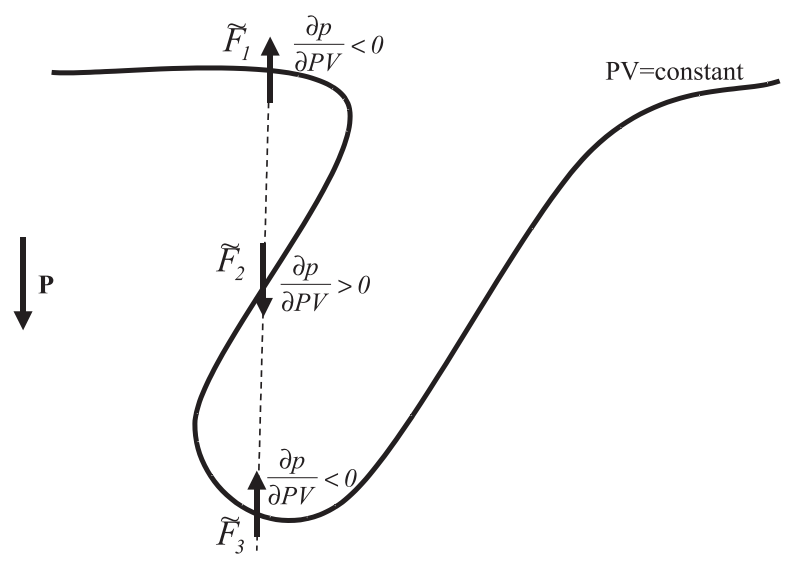

Fig. 1. Illustration of a tropopause fold 
PV ALONG A TRAJECTORY

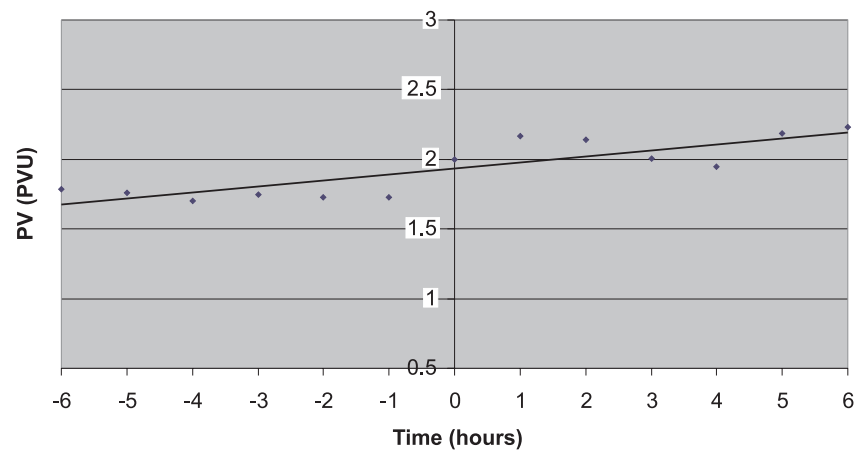

Fig. 2. Determination of the 12-hour mean $\mathrm{d} P V / \mathrm{d} t$ with a linear regression of $P V$ versus time. The trajectory model gives output data every hour $\left(1 P V U=10^{-6} \mathrm{~K} \mathrm{~m}^{2} \mathrm{~kg}^{-1} \mathrm{~s}^{-1}\right)$

$\tilde{F}=\frac{1}{g}\left|\frac{\partial p}{\partial P V}\right| \frac{\overline{\mathrm{d} P V}}{\mathrm{~d} t}$,

where $\overline{\mathrm{d} P V / \mathrm{d} t}$ is the mean $\mathrm{d} P V / \mathrm{d} t$ in the 12 -h time interval obtained by a linear least square regression of the $P V$ along the trajectory versus time, and $|\partial p / \partial P V|$ is the mean of $|\partial p / \partial P V|$ along the 12-h trajectory.

The value of $\tilde{F}$ is calculated for each gridpoint of the 3-D-domain (described in Sect. 3), by calculating $P V$ and $|\partial p / \partial P V|$ along the 6-h forward and backward trajectory that start at the gridpoint. The value of $\tilde{F}$ is then attributed to the gridpoint and the starting time of the trajectories. To compute the flux $\tilde{F}$ in a tropopause fold at a particular latitude and longitude, the fluxes through the three surfaces where $P V=$ constant are summed so that Eq. (3) becomes:

$\tilde{F}=\tilde{F}_{1}+\tilde{F}_{2}+\tilde{F}_{3}$

where subscript 1 denotes calculation at the top of the fold, 2 at the middle tropopause and 3 at the bottom of the fold (see Fig. 1).

According to Eq. (2), an air mass flux across a $P V$ surface implies a material change of $P V$. The $P V$ of a single air parcel can be changed by diabatic heating gradients and friction (Hoskins et al., 1985). In addition, the gridbox mean $P V$ can be changed by mixing (Shapiro, 1980). The computed fluxes also suffer from noise due to errors in the atmospheric dataset, the computed trajectories and the numerical method to calculate $P V$.

$\tilde{F}$ is called statistically significant if the probability that $\tilde{F}$ differs from zero is more than $99 \%$. Here to a Student's $t$-test is applied to the value of $\tilde{F}$ and its standard deviation, where the standard deviation of $\tilde{F}$ is computed from the standard deviations of $\overline{\mathrm{d} P V / \mathrm{d} t}$ and $\overline{|\partial p / \partial P V|}$.

\subsection{Trajectory model}

To calculate the trajectories, we have used the KNMI trajectory model (as described by Scheele et al., 1996).
This model calculates the three-dimensional displacement of air parcels for each time-step $\delta t$ using an iterative scheme after Petterssen (1940). In the present study $\delta t=10 \mathrm{~min}$. The input circulation data are obtained from the ECMWF (see Sect. 2.3). Spatial interpolation [linear in the horizontal and linear in the vertical with $\log (p)]$ and temporal interpolation (quadratic) are applied to the input data.

In the present study three-dimensional rather than isentropic trajectories are calculated in order to include diabatic effects in the calculations of $\tilde{F}$. Moreover, the three-dimensional trajectories are believed to be more accurate as is concluded, e.g. by Stohl et al. (1995).

To calculate the $P V$ at place $X$ and at time $t$, the $P V$ is first calculated at the three data input times closest to time $t$ at place $X$ and is then quadratically interpolated to the time $t$.

\subsection{ECMWF-data}

For this study we use ECMWF circulation and temperature data of the first five days of a forecast run, which is initialised on 13 April 1998, 12 GMT. The data are at a $1^{\circ} \times 1^{\circ}$ horizontal grid, at 31 vertical levels. Around the tropopause the vertical resolution is about $25 \mathrm{hPa}$. The model data are stored every $6 \mathrm{~h}$. We use forecast data rather than analysed data in order to have a physically consistent data set, in which the modelled quantities (in particular the $P V$ ) are not disturbed by the addition of new observations. Since the difference between the $+96 \mathrm{~h}$ model forecast of the $500-\mathrm{hPa}$ geopotential height field for 12 GMT on 17 April 1998 and the verifying analyses is very small, the forecast data give a realistic representation of the synoptic-scale processes in the considered period.

\section{Results}

The air mass flux across a $P V$-surface $(\tilde{F})$ is calculated for an extratropical cyclone over the North Sea between 14 and 17 April 1998. $\tilde{F}$ is calculated on two different 3-D grids with a horizontal resolution of $1^{\circ} \times 1^{\circ}$ : one with $P V$ as the vertical coordinate (fluxes are calculated across the $1,1.5,2,3,4,6,8$ and 10 $P V U$ surfaces) and one with pressure as the vertical coordinate (from $600 \mathrm{hPa}$ to $100 \mathrm{hPa}$, with a vertical resolution of $25 \mathrm{hPa}$ ). The horizontal domain is the area between $35^{\circ} \mathrm{W}$ and $25^{\circ} \mathrm{E}$ and between $20^{\circ} \mathrm{N}$ and $75^{\circ} \mathrm{N}$.

\subsection{Synoptic situation}

The solid lines in Fig. 3 show the $500-\mathrm{hPa}$ geopotential height field for the period between 14 and 17 April 1998. On April 14 the cyclone has already reached maturity, on April 16 the strength of the cyclone is 

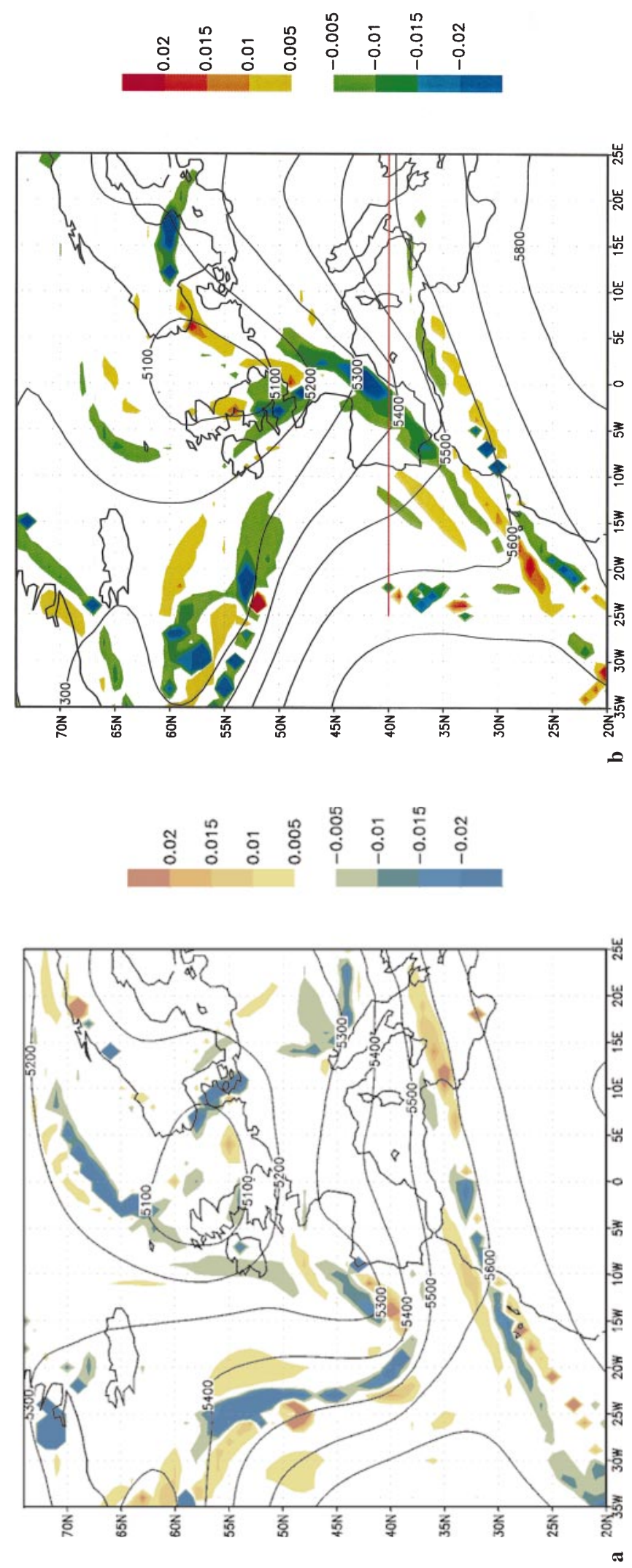

maximal and on April 17 the cyclone has weakened considerably. The centre of the cyclone as seen on the $500-\mathrm{hPa}$ geopotential height map hardly moves; it lies at the northern part of the North Sea during the entire period considered.
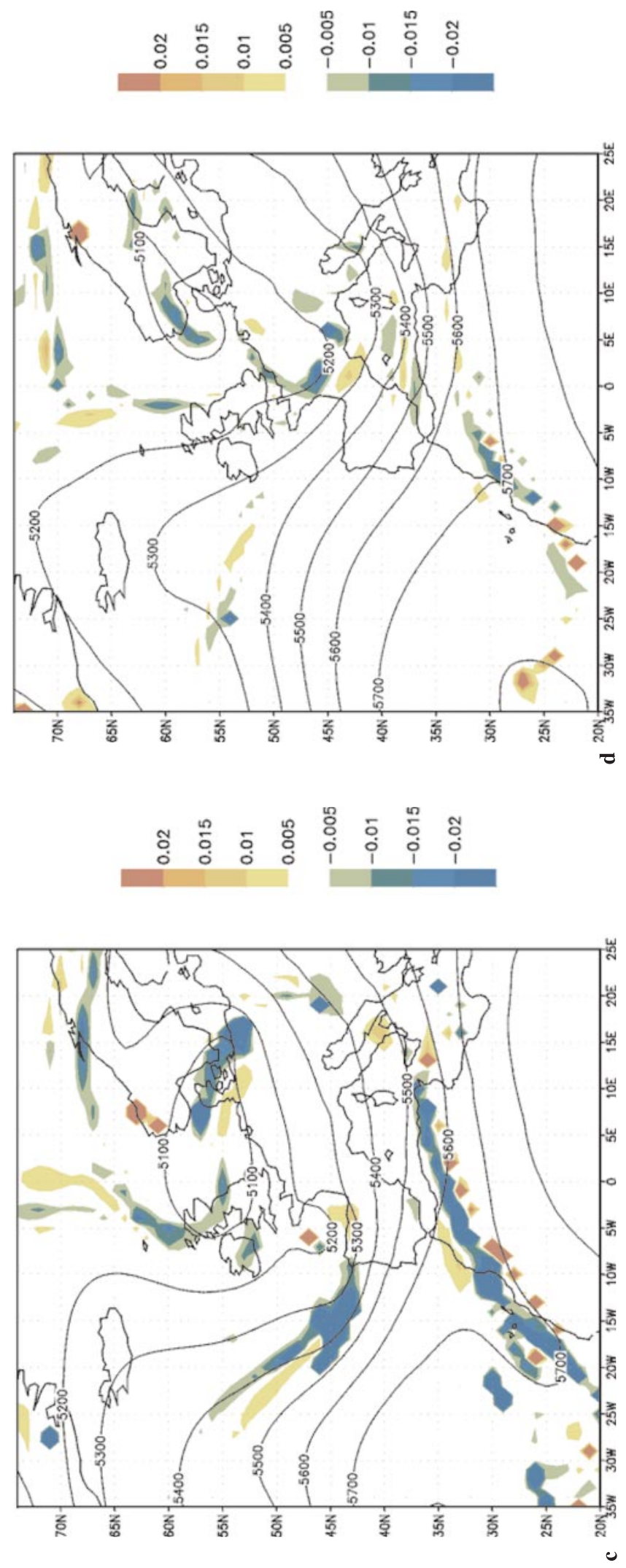

\subsection{Geographical distribution of the flux across $P V$-surfaces}

The tropopause is generally defined as a surface of constant $P V$. The values mostly used vary between 1.5 
Fig. 3a-d. $\tilde{F}$ across the $2 P V U$ surface (shaded, in $\mathrm{kg} \mathrm{m}^{-2} \mathrm{~s}^{-1}$ ) together with the $500 \mathrm{hPa}$ geopotential height (contours, in $\mathrm{m}$ ). Positive values denote transport from the troposphere to the stratosphere. $\tilde{F}$ is shown for a 14 April, b 15 April, c 16 April and d 17 April, 1998, all at 12 GMT

and 3.5 PVU. When the tropopause is defined as the 2 $P V U$ surface, which is an often used value, the flux across that surface can be considered as the crosstropopause flux.

Figure 3 also shows the field of $\tilde{F}$ across the $2 P V U$ surface for the four different days. The field is dominated by elongated patterns of large downward and small upward fluxes. During the entire period a region with large downward fluxes far south of the cyclone centre (along the northwest coast of Africa) is visible. On April 14 and April 16 (Fig. 3a, c), a region with large upward fluxes can be found just south of this region.

Two other regions with large downward fluxes are present on April 14: one north of the cyclone centre and one southwest of the cyclone centre, west of the 500-hPa trough. On April 15 the latter region has separated into two regions, one west and one south of the cyclone centre, in the middle of the $500-\mathrm{hPa}$ trough. The region with large downward fluxes north of the centre on the 14th has moved eastward towards southeast Scandinavia. On April 16 a region with large downward fluxes is again identified southwest of the cyclone centre. Two other bands with large downward fluxes are present: the first just east of the cyclone centre, the other starting in the cyclone centre and then curling to the north. On April 17 the large downward fluxes southwest of the cyclone have vanished. The regions with large downward fluxes occur near the cyclone centre and just south of it.

The flux across the $P V$-surfaces decreases with increasing $P V$. The $|\partial p / \partial P V|$-field and thus the $\tilde{F}$-field across $P V$-surfaces lower than $2 P V U$ is very noisy (not shown).

Figure 4 shows $\tilde{F}$ across the $2 P V U$ surface on 14 April at 12 GMT with significance criterion, as described in Sect. 2.1. Although the three areas with large downward fluxes can still be identified, it is clear that in large parts of these areas the computed fluxes are not significant.

This can be understood as follows. Along trajectories passing a tropopause fold, $P V$ is changing relatively rapid. $\mathrm{d} P V / \mathrm{d} t$ along those trajectories is relatively large but noisy. As a result, the signal to noise ratio along a trajectory passing a fold is generally low and consequently the computed $\tilde{F}$ is often not statistically significant, i.e. the probability that the real flux differs from zero is less than $99 \%$. In other areas where the flux is statistically insignificant, the flux itself is very small. In the entire domain $87 \%$ of the gridpoints in Fig. 4 have significant fluxes, $88 \%$ have significant $\mathrm{d} P V / \mathrm{d} t$ and $99 \%$ have significant $|\partial p / \partial P V|$. Similar values are found for the other days.

\subsection{Decomposition of the flux}

In order to gain understanding of the structures in the $\tilde{F}$-field, $\tilde{F}$ across the $2 P V U$ surface on 14 April is decomposed in $\mathrm{d} P V / \mathrm{d} t$ (Fig. 5a) and $|\partial p / \partial P V|$ (Fig. 5b). After comparing Fig. 5a, b with Fig. 3a, one can conclude that a condition for large (downward) fluxes is a large $|\partial p / \partial P V|$. A large $\mathrm{d} P V / \mathrm{d} t$ does not imply a large flux when $|\partial p / \partial P V|$ is small. In the southwestern part of Iceland, for example, a large $\mathrm{d} P V / \mathrm{d} t$ but a small $|\partial p / \partial P V|$ is present, which results in a small flux. When $|\partial p / \partial P V|$ is small, the vertical distance between the different $P V$-surfaces is small so that a large $P V$-change does not imply that much air has crossed a $P V$-surface.

The $|\partial p / \partial P V|$-field at the $2 P V U$ surface appears to be directly coupled to the pressure field at this surface (Fig. 5c), i.e. the tropopause height. The $|\partial p / \partial P V|$ and thus the flux is large in the areas where the tropopause pressure gradient is large (i.e. where the tropopause slopes) and in small-scale areas where the tropopause pressure itself is high (i.e. where the tropopause height is small), which can be understood from Fig. 6. These conditions are valid in the tropopause folds, where the slope of the tropopause is very large (see Fig. 1), and at the edge of a more extended lowering of the tropopause in the centre of a cyclone.

\subsection{Vertical cross-sections of the air mass flux across $P V$-surfaces}

In order to obtain a clearer understanding of the structure of the field of $\tilde{F}$ in tropopause folds, vertical cross sections of $\tilde{F}$ across these folds have been calculated. Figure 7 shows a cross-section of $\tilde{F}$ on 15 April, at 12 GMT along $40^{\circ} \mathrm{N}$, with pressure as the vertical coordinate. A region with large downward fluxes on the eastside of the tropopause trough and a region with smaller upward fluxes in the tropopause ridges west and east of this trough are clearly distinguished. Many insignificant fluxes are found below the $1 P V U$ surface, where $|\partial p / \partial P V|$ is very large and noisy, resulting in a low signal to noise ratio. In most other tropopause folds (not shown), the region with the largest downward fluxes is also found on the eastside; in some folds this maximum is found in the middle of the fold, but not in the western part. The presence of regions with upward fluxes in tropopause ridges is also found to be a returning feature.

The maximum found in downward fluxes in tropopause folds is expected to be a reliable result for the following reason. A tropopause fold can be looked at as a small-scale lowering of the tropopause. Above a lowered tropopause, the $P V$ is anomalously high. According to the definition of $P V$, this would mean an anomalously high positive relative vorticity and an anomalously high $\partial \theta / \partial p$ in this $P V$-anomaly. The wind speed is therefore highest on both sides of the $P V$ anomaly, as can be verified from ECMWF-data for April 15 as seen in Fig. 8. The wind maxima cause a large shear in the surrounding areas. This wind shear causes strong mixing of air masses in the tropopause fold. Since the $P V$-gradient is relatively high in this 

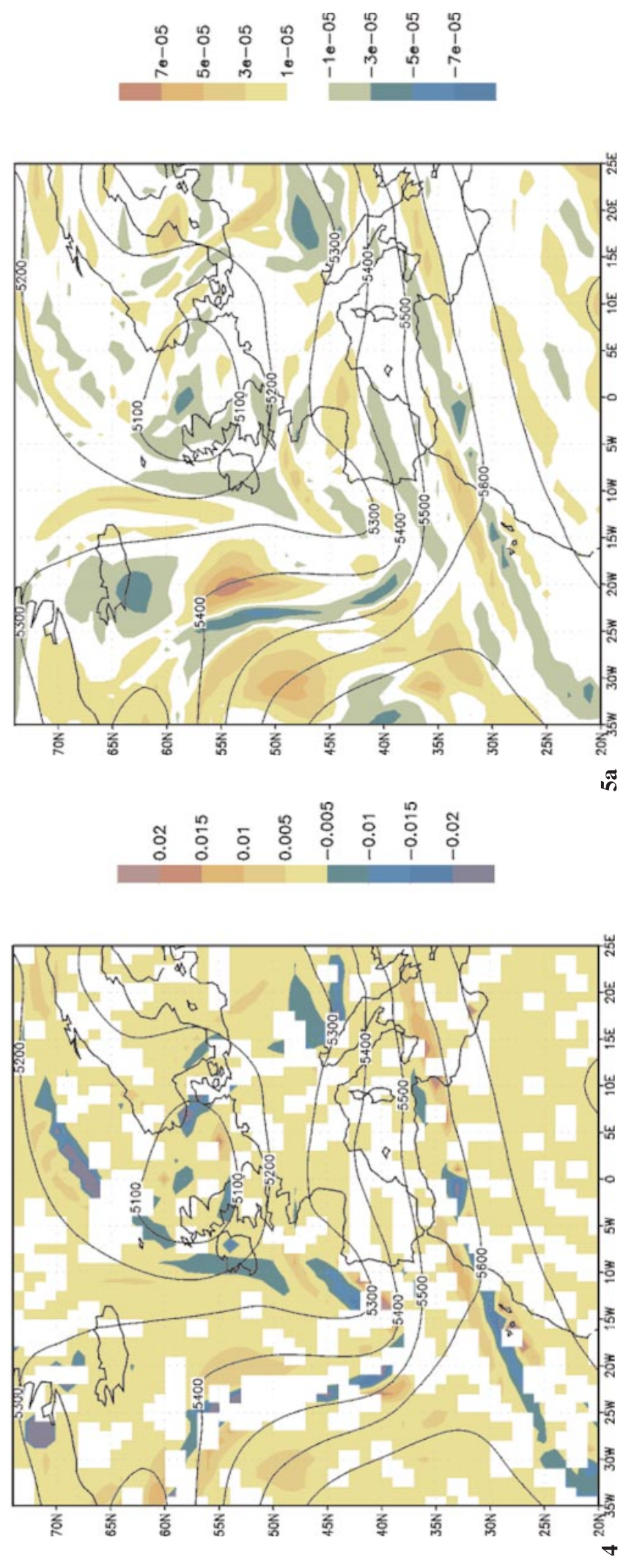

region, this mixing of air masses implies a strong $P V$-mixing. Comparing Fig. 8 with Fig. 7 , one can clearly see that the fluxes are largest in the regions where the wind shear is maximal. In these regions, $P V$ -

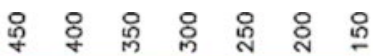
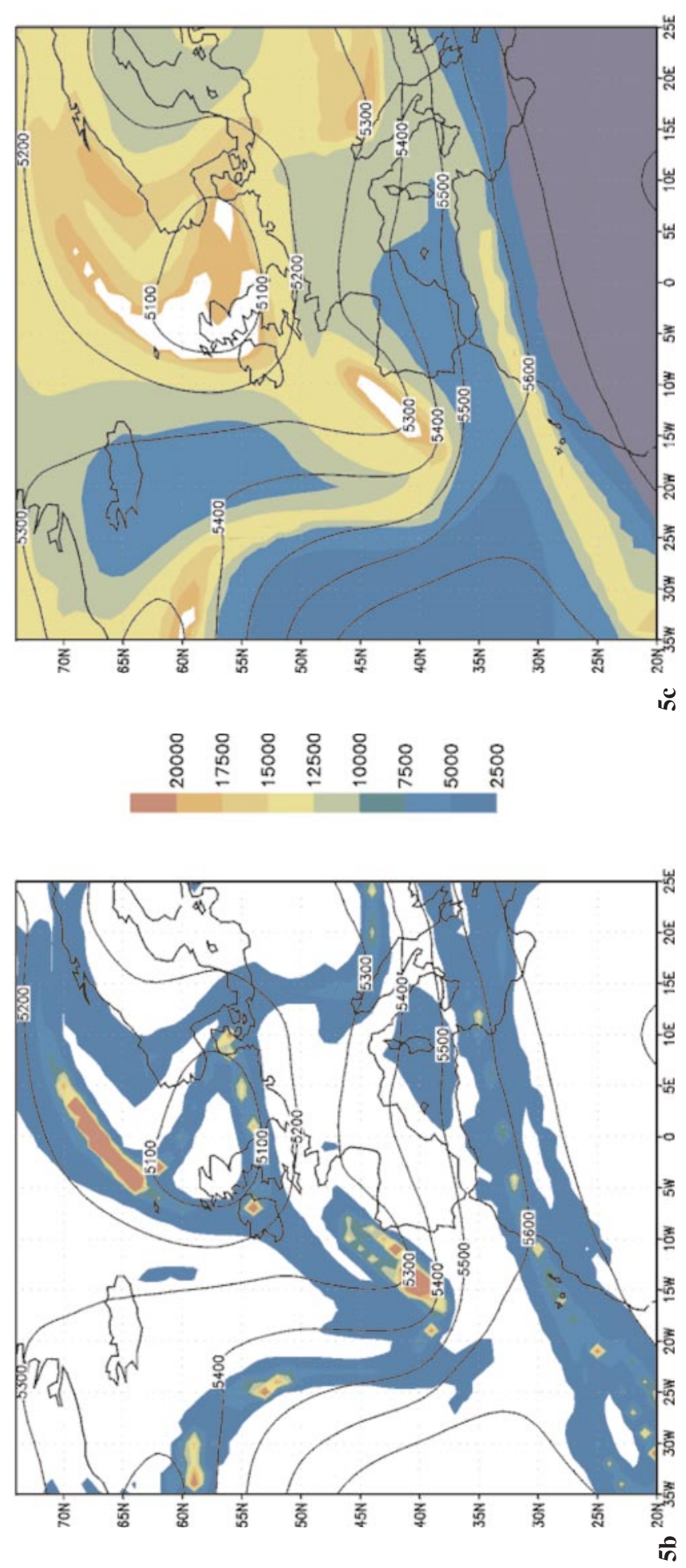

mixing is thought to cause the large fluxes. The large downward fluxes found in tropopause folds are therefore thought to be a reliable result, at least in a qualitative sense. 
Fig. 4. $\tilde{F}$ across the $2 P V U$ surface (shaded, in $\mathrm{kg} \mathrm{m}^{-2} \mathrm{~s}^{-1}$ ) together with the $500 \mathrm{hPa}$ geopotential height (contours, in m) on 14 April 12 GMT, with significance criterion. Where $\tilde{F}$ is statistically insignificant, the corresponding gridbox has been left blank

Fig. 5a-c. Decomposition of $\tilde{F}$ across the $2 P V U$ surface on 14 April 12 GMT (as shown in Fig. 3a) in $\mathrm{d} P V / \mathrm{d} t\left(\mathbf{a}\right.$, shaded, in $\left.P V U \mathrm{~s}^{-1}\right)$ and $|\partial p / \partial P V|\left(\mathbf{b}\right.$, shaded, in $\left.\mathrm{Pa} P V U^{-1}\right)$ together with the $500 \mathrm{hPa}$ geopotential height (contours, in $\mathrm{m}$ ). The colours in $\mathbf{c}$ show the pressure (in $\mathrm{hPa}$ ) of the $2 P V U$ surface

The tropopause fold found along the northwest coast of Africa is thought to lie on a peculiar position. To validate the position of this tropopause fold, GOME (Global Ozone Monitoring Experiment) total ozone columns have been considered. These data (not shown here) show a maximum in the total ozone column, which

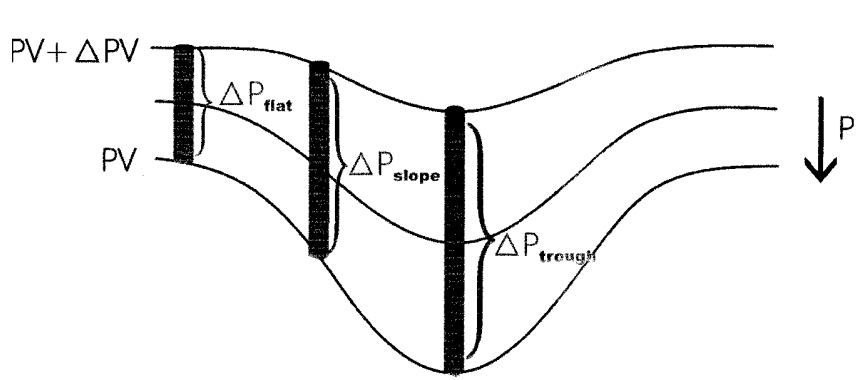

Fig. 6. Illustration of $|\partial p / \partial P V|$ around a tropopause trough. $|\partial p / \partial P V|$ at a sloping tropopause and at a tropopause trough is generally larger than $|\partial p / \partial P V|$ at a flat tropopause implies a lowering of the tropopause, virtually along the tropopause fold. The tropopause fold found with its large downward fluxes along the northwest coast of Africa is, therefore, expected to be a reliable result.

\subsection{Area-averaged upward and downward fluxes}

As is described in the introduction, the ratio between the upward and downward fluxes should be known in order to calculate the cross-tropopause fluxes of chemical species. To make an impression of this ratio, all upward and downward fluxes (without significance criterion) are added separately and are then averaged over the entire domain (see Table 1). In this calculation, fluxes larger than $0.1 \mathrm{~kg} \mathrm{~m}^{-2} \mathrm{~s}^{-1}$ and smaller than $-0.1 \mathrm{~kg} \mathrm{~m}^{-2} \mathrm{~s}^{-1}$ are assumed to be non-physical and are set to $0.1 \mathrm{~kg} \mathrm{~m}^{-2} \mathrm{~s}^{-1}$ and $-0.1 \mathrm{~kg} \mathrm{~m}^{-2} \mathrm{~s}^{-1}$, respectively. It is striking to see that the ratio $R$ is smallest on April 16, when the strength of the cyclone is maximal, and largest on April 17, when the cyclone has weakened. The ratio between the area averaged upward and downward crosstropopause fluxes appears to decrease with increasing strength of the cyclone.

\section{Discussion}

In this section the parametrisation of $P V$-mixing in the ECMWF-model and the method for calculating the flux across a $P V$-surface will be discussed. In Sect. 4.3, the ratios found between the area-averaged upward and

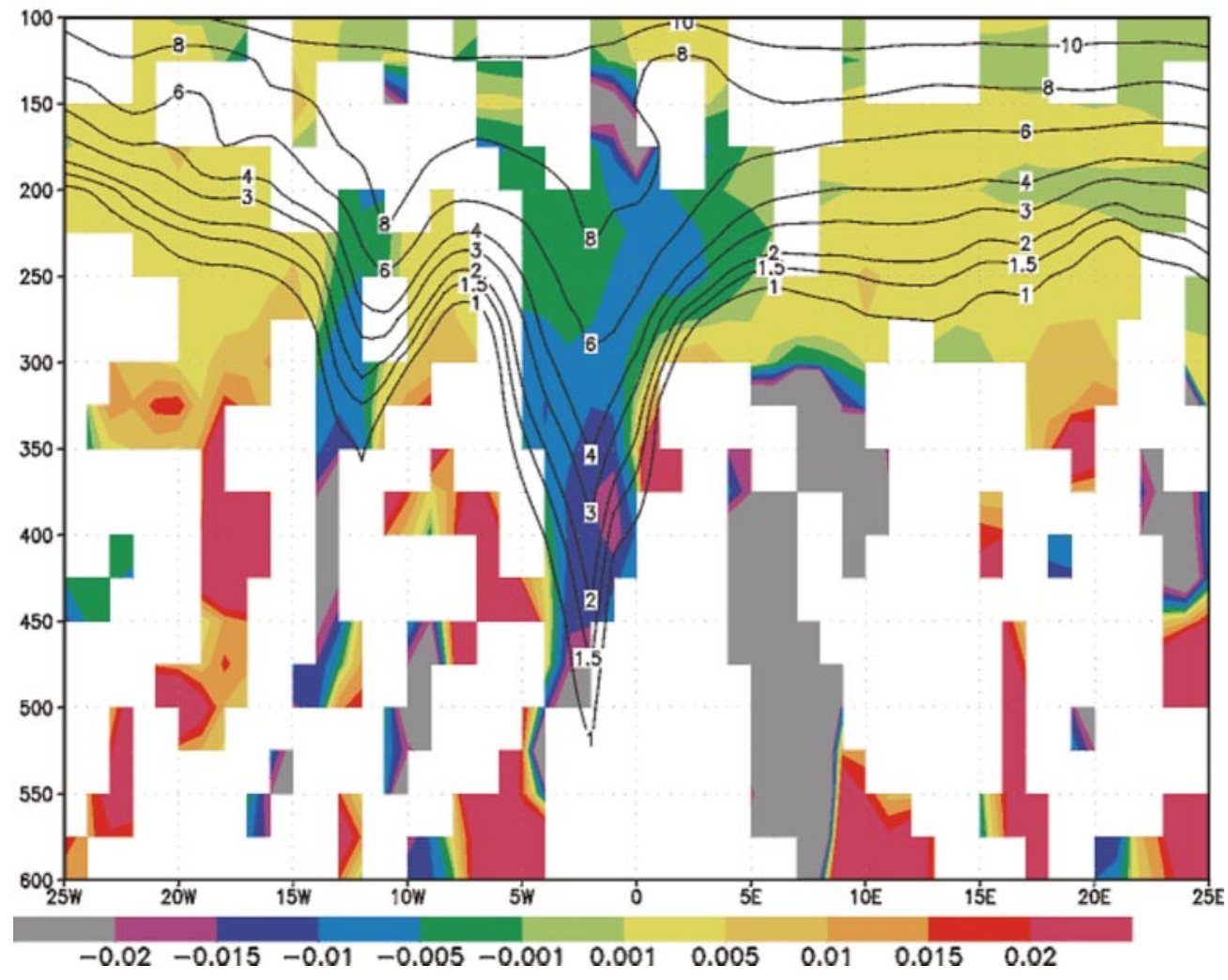

Fig. 7. Vertical cross section of $\tilde{F}$ (shaded, in $\mathrm{kg} \mathrm{m}^{-2} \mathrm{~s}^{-1}$ ) on 15 April 12 GMT along $40^{\circ} \mathrm{N}$ (which is the red line in Fig. 3b), with significance criterion (i.e. spaces are left blank where $\tilde{F}$ is statistically insignificant), with pressure as the vertical coordinate, together with isolines of $P V$ (in $P V U$ ) 


\section{Cross section between $40.0 \mathrm{~N} 335.0 \mathrm{E}$ and $40.0 \mathrm{~N} 385.0 \mathrm{E}$ on 13-4-1998 at $12 Z+48$ on model levels}

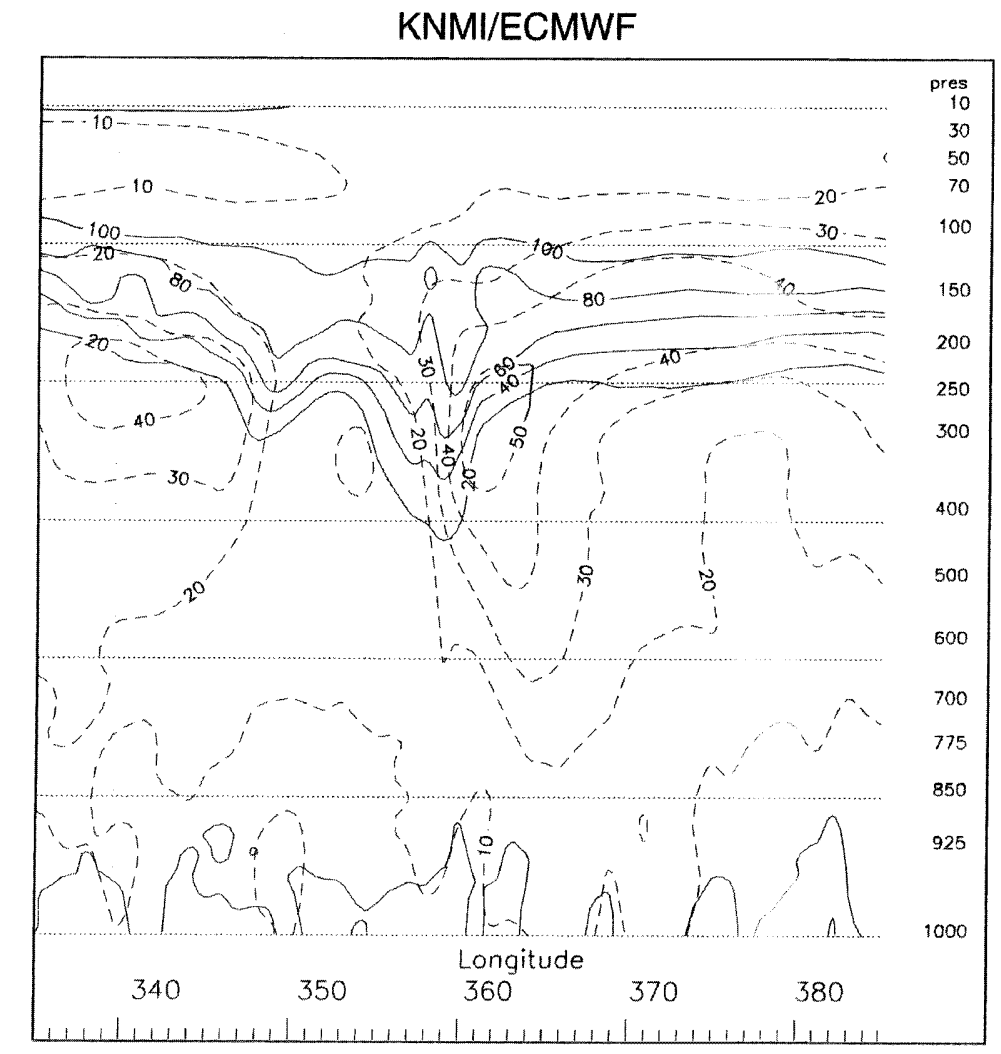

Fig. 8. Vertical cross section of the wind speed (dotted lines, in $\mathrm{m} \mathrm{s}^{-1}$ ) on 15 April 12 GMT along $40^{\circ} \mathrm{N}$ (which is the red line in Fig. 3b), with pressure as the vertical coordinate (in $\mathrm{hPa}$ ), together with some isolines of $P V$ (solid lines, in $P V U^{*} 10$ ) downward fluxes will be compared with those found in previous studies.

\subsection{Parametrisation of $\mathrm{PV}$-mixing in the ECMWF-model}

As described in Sect. 2.1, one of the sources of the gridbox mean $P V$ (and thus the stratosphere-troposphere exchange as calculated in this study) is $P V$-mixing. In the real atmosphere, the $P V$ of a single air parcel can only be changed by diabatic heating gradients and friction. In a numerical (prognostic) model, the change of $P V$ due to mixing is a result of the model formulation of subgrid-

Table 1. Domain-averaged upward (Fup), downward (Fdown) and net (Fnet) fluxes (in $\mathrm{kg} \mathrm{m}^{-2} \mathrm{~s}^{-1}$ ) and the ratio of the domainaveraged upward and downward fluxes $(R=\mid F$ up $/ F$ down $\mid)$ across the $2 P V U$ surface for $14,15,16$ and 17 April 1998, 12 GMT

\begin{tabular}{lllll}
\hline Time & Fup & Fdown & Fnet & $R$ \\
\hline 98041412 & $1.69 \mathrm{E}-03$ & $-2.24 \mathrm{E}-03$ & $-5.44 \mathrm{E}-04$ & 0.757 \\
98041512 & $1.40 \mathrm{E}-03$ & $-1.78 \mathrm{E}-03$ & $-3.83 \mathrm{E}-04$ & 0.785 \\
98041612 & $1.52 \mathrm{E}-03$ & $-2.39 \mathrm{E}-03$ & $-8.77 \mathrm{E}-03$ & 0.633 \\
98041712 & $1.29 \mathrm{E}-03$ & $-1.10 \mathrm{E}-03$ & $1.84 \mathrm{E}-04$ & 1.167 \\
\hline
\end{tabular}

scale processes. A restriction of a model is that it can not calculate the evolution of the properties of every single air parcel in the atmosphere explicitly. Instead, the quantities are calculated on a grid with a finite spatial resolution. The quantities calculated in a model are therefore gridbox mean rather than local quantities. The same applies to the $P V$ computed along a trajectory. Therefore, in the absence of diabatic heating gradients and friction, mixing of air masses with different $P V$ can lead to a change in the gridbox mean $P V$, although the $P V$ of the individual air parcels is conserved.

The $P V$-change computed from gridbox mean circulation data is given by (for simplicity the 2-dimensional situation is considered):

$$
\begin{aligned}
\frac{\mathrm{d} \overline{P V}}{\mathrm{~d} t} & \equiv \frac{\partial \overline{P V}}{\partial t}+\bar{u} \frac{\partial \overline{P V}}{\partial x}+\bar{v} \frac{\partial \overline{P V}}{\partial y} \\
& =-\left[\frac{\partial \overline{u^{\prime} P V^{\prime}}}{\partial x}+\frac{\partial \overline{v^{\prime} P V^{\prime}}}{\partial y}\right],
\end{aligned}
$$

where the overbar denotes gridbox mean values and the accent denotes deviations from those mean values.

The right-hand side of this equation, the divergence of the eddy $P V$-flux, is a subgrid process, which is not computed explicitly. Instead, subgrid processes are 
parametrised in terms of the known gridbox mean quantities. In the ECMWF-model, the subgrid-scale fluxes of the model variables that determine the $P V$ (vorticity, divergence and temperature) are parametrised, rather than the eddy $P V$-flux itself. The quality of these parametrisations in the ECMWF-model determines the quality of the results of this study.

A second, possibly even more important contribution to the divergence of the eddy $P V$ flux is model numerical diffusion.

\subsection{Method for calculating the flux across a PV-surface}

4.2.1 Calculation of the fluxes. Because of numerical errors due to finite time and space differencing, finding an appropriate method for diagnosing the local and instantaneous flux across a $P V$-surface is not straightforward. Siegmund et al. (1996) have introduced the "advection method", in which the space terms are selectively averaged over time in an Eulerian framework. In this work we have circumvented these time differencing problems by working in a Lagrangian framework. The main remaining problem is that the data suffer from noise. Instant values of $\mathrm{d} P V / \mathrm{d} t$ can therefore be unreliable. To cope with this problem, a certain kind of averaging is necessary. The instant flux in a gridpoint has therefore been computed from data along 6-h forward and backward trajectories starting at the gridpoint.

A second approximation that has been made concerns the calculation of the $P V$ along the trajectories. The gridbox averaged $P V$, used in numerical atmospheric models, should be calculated according to:

$\overline{P V}=\overline{\frac{\partial \theta}{\partial p}(\varsigma+f)}=\frac{\overline{\partial \theta}}{\partial p} \overline{(\zeta+f)}+\overline{\left(\frac{\partial \theta}{\partial p}\right)^{\prime}(\zeta+f)^{\prime}}$,

where the overbar denotes the gridbox mean value and the accent denotes the deviation from that value.

In our calculation of $\overline{P V}$ we were forced to neglect the second term on the right hand side, since the ECMWFmodel only provides gridbox mean quantities.

4.2.2 Averaging period. The averaging period for the calculation of $F$ (Eq. 3) has been varied to see how this affects the results. With decreasing period, the reduction of the noise in the results, which was made by averaging, decreases and less values of $\tilde{F}$ are statistically significant. As a suitable time period for averaging $\mathrm{d} P V / \mathrm{d} t$ and $|\partial p / \partial P V|, 12 \mathrm{~h}$ is found to work well. Averaging over a longer period does not decrease the noise substantially, but artificially smoothes out the cross- $P V$ fluxes.

\subsubsection{Comparison with the Lagrangian flux calculation of} Wirth and Egger (1999). As described in the introduction, Wirth and Egger (1999) also used a Lagrangian method to diagnose the cross-tropopause air mass flux. Although the concept of their method is similar to the method applied in this study, there are some noteworthy differences. The similarity is that in both methods a quantity is considered along a trajectory, which is the $P V$ in the present study and the pressure in their study. The pressure difference between the endpoint of a trajectory that started at the tropopause and the tropopause at that endpoint, is then taken by Wirth and Egger (1999) as a measure of the cross-tropopause flux.

A difference with our method is that every three hours a reinterpolation of their trajectories to a regular grid is performed in order to avoid a too strong accumulation or dilution of points, which introduces some smoothing. Our method circumvents this problem by calculating forward and backward trajectories starting at a gridpoint and attributing the computed flux to this gridpoint.

A second difference is that Wirth and Egger (1999) compute the cross-tropopause flux from information at only the begin and the end of the trajectory, whereas in the present study the averaged $P V$-rate of change along the trajectory, estimated by a linear least square method, and the trajectory-mean value of $|\partial p / \partial P V|$ are used to calculate the flux. Our results are, therefore, expected to be less subjected to noise.

\subsection{Comparison of $\mathrm{Fup} / \mathrm{F}$ down with previous studies}

Table 2 shows different values of $R(=\mid F$ up $/ F$ down $\mid)$ found in different studies with different methods. Before
Table 2. Calculations of $R$ $(=\mid F$ up $/ F$ down $\mid)$ from previous studies and the present study

\begin{tabular}{|c|c|c|c|c|c|}
\hline Source & $R$ & $\begin{array}{l}\text { Averaging } \\
\text { period }\end{array}$ & $\begin{array}{l}\text { Averaging } \\
\text { area }\end{array}$ & Method & Model \\
\hline $\begin{array}{l}\text { Spaete et al. } \\
\text { (1994) }\end{array}$ & 0.4 & 1 day & $\begin{array}{l}\text { Area around } \\
\text { tropopause fold, } \\
\text { travelling with } \\
\text { system }\end{array}$ & $\begin{array}{c}\text { Wei- } \theta \text { across } \\
3 P V U\end{array}$ & Mesoscale \\
\hline $\begin{array}{c}\text { Lamarque and } \\
\text { Hess (1994) }\end{array}$ & 0.79 & 4 days & $\begin{array}{l}\text { Area around } \\
\text { extratropical } \\
\text { cyclone travelling } \\
\text { with system }\end{array}$ & $\begin{array}{l}\text { Wei- } P V \text { across } \\
\quad 2 P V U\end{array}$ & Mesoscale \\
\hline $\begin{array}{l}\text { Siegmund et al. } \\
\text { (1996) }\end{array}$ & 0.97 & Month & $28^{\circ} \mathrm{N}-90^{\circ} \mathrm{N}$ & $\begin{array}{c}\text { Wei- } p \text { across } \\
3.5 P V U\end{array}$ & $\begin{array}{l}\text { ECMWF, } \\
\text { first guess } \\
\text { data }\end{array}$ \\
\hline Present study & $0.63-1.17$ & $(12 \mathrm{~h})$ & $\begin{array}{l}35^{\circ} \mathrm{W}-25^{\circ} \mathrm{E} \\
20^{\circ} \mathrm{N}-75^{\circ} \mathrm{N}\end{array}$ & $\begin{array}{l}\text { Trajectories, } \\
\text { Wei- } P V \\
\text { across } 2 P V U\end{array}$ & $\begin{array}{l}\text { ECMWF, } \\
\text { first guess } \\
\text { data }\end{array}$ \\
\hline
\end{tabular}


comparing our values with the other values from Table 2, one should realise that $R$ can be strongly case-dependent.

In our results, the largest downward fluxes have been found in tropopause folds. From Table 2 it appears that $R$ decreases if fewer fluxes outside the tropopause fold are taken into account in the calculation of $R$.

In Spaete et al. (1994) and Lamarque and Hess (1994), $R$ is calculated in a relatively small area around, respectively, a tropopause fold and an extratropical cyclone, whereas in our case, $R$ is calculated averaged over a larger area around an extratropical cyclone. Siegmund et al. (1996), finally, computed $R$ for a whole month and for a much larger area.

The domain-averaged upward (Fup) and downward (Fdown) fluxes are comparable to the values found by Lamarque and Hess $\left(1.68 \times 10^{-3} \mathrm{~kg} \mathrm{~m}^{-2} \mathrm{~s}^{-1}\right.$ and $2.12 \times 10^{-3} \mathrm{~kg} \mathrm{~m}^{-2} \mathrm{~s}^{-1}$, respectively) and Spaete et al. $\left(5.79 \times 10^{-3} \mathrm{~kg} \mathrm{~m}^{-2} \mathrm{~s}^{-1}\right.$ and $2.31 \times 10^{-3} \mathrm{~kg} \mathrm{~m}^{-2} \mathrm{~s}^{-1}$, respectively).

\section{Conclusions}

In this work a Lagrangian method for diagnosing the air mass flux across $P V$-surfaces, in particular across the tropopause, has been applied. Several aspects of the method are new compared to previous studies. The flux is computed from the $P V$ and $|\partial p / \partial P V|$ along 12-h trajectories that pass the gridpoint for which the flux is estimated. The trajectories are computed from ECMWF circulation data. The error in the flux across $P V$-surfaces is quantified and used to determine the statistical significance of the flux.

The computed field of the air mass flux across $P V$ surfaces is dominated by elongated patterns of statistically significant large downward and small upward fluxes. The downward fluxes mainly occur in regions of a tropopause fold, whereas the upward fluxes are found near tropopause ridges. The area-averaged upward (Fup) and downward (Fdown) fluxes, which both lie between 1 and $2.5 \times 10^{-3} \mathrm{~kg} \mathrm{~m}^{-2} \mathrm{~s}^{-1}$, are comparable to the values found by previous investigators. The ratio between the area averaged upward and downward crosstropopause fluxes appears to decrease with increasing strength of the cyclone.

The results are thought to be reliable, at least in a qualitative sense, because the largest downward fluxes in the tropopause fold occur in regions with maximum wind shear, where $P V$-mixing is thought to cause stratosphere-troposphere exchange. The geographical agreement between tropopause folds with large downward fluxes and the high total ozone values is good. Although several approximations have been made in the applied new Lagrangian method, this method appears to be an appropriate tool for diagnosing $\mathrm{d} P V / \mathrm{d} t$ in general and stratosphere-troposphere exchange in particular.
Acknowledgements. We thank Rinus Scheele for his support he gave concerning the KNMI trajectory model. We also would like to thank Geert-Jan Roelofs and Anastasios Kentarchos (both from the Institute of Marine and Atmospheric Research, Utrecht University, the Netherlands) for their helpful suggestions. Comments by two anonymous reviewers helped improve the manuscript, and were greatly appreciated.

Topical Editor D. Murtagh thanks two referees for their help in evaluating this paper.

\section{References}

Brewer, A. M., Evidence for a world circulation provided by the measurements of helium and water vapour distribution in the stratosphere, Q. J. R. Meteorol. Soc., 75, 351-363, 1949.

Dobson, G. M. B., Origin and distribution of polyatomic molecules in the atmosphere, Proc. R. Meteorol. Soc., A236, 187-193, 1956.

Gettelman, A., and A. H. Sobel, Direct diagnoses of stratospheretroposphere exchange, J Atmos Sci (in press) 1999.

Hoerling, M. P., T. K. Schaack, and A. J. Lenzen, A global analysis of stratospheric-tropospheric exchange during northern winter, Mon. Weather Rev., 121, 162-172, 1993.

Holton, J. R., P. H. Haynes, M. E. McIntyre, A. R. Douglass, R. B. Rood, and L. Pfister, Stratosphere-troposphere exchange, Rev. Geophys., 33, 403-439, 1995.

Hoskins, B. J., M. E. McIntyre, and A. W. Robertson, On the use and significance of isentropic potential vorticity maps, Q.J.R. Meteorol. Soc., 111, 877-946, 1985.

IPCC (Intergovernmental Panel on Climate Change), special report on 'Aviation and the global atmosphere', Cambridge University Press, 1999.

Lamarque, J., and P. G. Hess, Cross-tropopause mass exchange and potential vorticity budget in a simulated tropopause folding, J. Atmos. Sci., 51, 2246-2269, 1994.

Petterssen, S., Weather analysis and forecasting. McGraw-Hill, New York, 221-223, 1940.

Scheele, M. P., P. C. Siegmund, and P. F. J. van Velthoven, Sensitivity of trajectories to data resolution and its dependence on the starting point: in or outside a tropopause fold, Meteorol. Appl., 3, 267-273, 1996.

Shapiro, M. A., Turbulent mixing within tropopause folds as a mechanism for the exchange of chemical constituents between the stratosphere and troposphere, J. Atmos. Sci., 37, 994-1004, 1980.

Siegmund, P. C., P. F. J. van Velthoven, and H. Kelder, Crosstropopause transport in the extratropical northern winter hemisphere, diagnosed from high-resolution ECMWF data, Q. J. R. Meteorol. Soc., 122, 1921-1941, 1996.

Spaete, P., D. R. Johnson, and T. K. Schaack, Stratospherictropospheric mass exchange during the Presidents' Day Storm, Mon. Weather Rev., 122, 424-439, 1994.

Stohl, A., G. Wotawa, P. Seibert, and H. Kromp-Kolb, Interpolation errors in wind fields as a function of spatial and temporal resolution and their impact on different types of kinematic trajectories, J. Appl. Meteorol., 35, 2149-2165, 1995.

Wei, M.-Y., A new formulation of the exchange of mass and trace constituents between the stratosphere and troposphere, J. Atmos. Sci., 44, 3079-3086, 1987.

Wernli H., and H. C. Davies, A Lagrangian-based analysis of extratropical cyclones. I: the method and some applications, Q. J. R. Meteorol. Soc., 123, 467-489, 1997.

Wirth, V., and J. Egger, Diagnosing extratropical synoptic-scale stratosphere-troposphere exchange: a case study, Q.J.R. Meteorol. Soc., 125, 635-655, 1999.

WMO, Scientific assessment of ozone depletion: 1994, Global ozone research and monitoring project, Report 37 World Meteorological Organization, Geneva, Switzerland, 1995. 